\title{
Epidemiology of adult Still's disease: estimate of the incidence by a retrospective study in west France
}

\author{
Genevieve Magadur-Joly, Eric Billaud, Jacques H Barrier, Yvon L Pennec, \\ Charles Masson, Philippe Renou, Alain Prost
}

Department of Internal Medicine, Nantes University Hospital, Nantes, France G Magadur-Joly E Billaud J H Barrier

Department of Rheumatology A Prost

Department of Internal Medicine, Brest University Hospital, Brest, France

Y L Pennec

Department of Rheumatology, Angers University Hospital, Angers, France C Masson

Department of Internal Medicine, Le Mans Hospital, Le Mans, France $P$ Renou

Correspondence to: Genevieve Magadur-Joly, Genevieve Magadur-Joly,
service de Medecine Interne II, Centre HospitaloUniversitaire, BP 1005, France.

France. 20 February 1995

\begin{abstract}
Objectives-To estimate the incidence of adult Still's disease (ASD) and to specify, if possible, associated factors.

Methods-A retrospective study of the populations of the Brittany and Loire regions in west France was made from 1 January 1982 to 31 December 1991. All internal medicine and rheumatology practitioners of these regions were consulted.
\end{abstract}

Results-Sixty-two (62) cases were reported (93\% response). The disease incidence calculated over five years was 0.16 per 100000 inhabitants in the study population. There was no sex bias (sex ratio 1.06 in ASD $v 1.05$ in the overall population. The mean age of the study population was 36 years, with two peaks of distribution at $15-25$ and $36-45$ years. A history of allergy was present in $23 \%$ of patients $(n=14)$. In two patients, it was possible to correlate an environmental allergen to exacerbation of ASD.

Conclusion-The yearly incidence of ASD was estimated to be 0.16 per 100000 inhabitants. However, it was not possible to incriminate any infectious, toxic, or genetic factors in exacerbation of the disease.

(Ann Rheum Dis 1995; 54: 587-590)

Adult Still's disease, first described in $1971,{ }^{1}$ is associated with septicaemic like fever, arthralgia, arthritis, cutaneous eruption, hyperleucocytosis, and occasional visceral involvement. Numerous clinical studies describing the diagnostic criteria and disease course have been published, ${ }^{2-11}$ but there remain many unknown factors in the aetiopathology and epidemiology of this disease. Several studies have examined associated risk factors, but none has discussed the incidence of the disease. The goal of this study was to identify the incidence of ASD, using a 10 year retrospective study of the population of west France.

\section{Patients and methods}

PATIENTS

The clinical criteria were divided into major (fever $>39^{\circ} \mathrm{C}$, arthralgia or arthritis, cutaneous eruption, leucocytosis $>10000$ ) and minor (pharyngitis, splenomegaly or lymph node enlargement, cytolysis, and absence of antinuclear antibodies or rheumatoid factor) categories, according to the definition of ASD proposed by Yamagushi et al, ${ }^{12}$ except that pericarditis or pleuritis were included as minor criteria. The modification was made for two reasons: until now, these criteria have been part of the established symptomatology of ASD, ${ }^{5}$ and the Japanese authors acknowledge that the clinical presentation in Eastern countries is slightly difference from that in Western countries, especially the higher frequency of pleuropericarditis in the West. ${ }^{12}$ Inclusion criteria for diagnosis required the presence of at least five of the defined clinical criteria including two major ones, and the absence of all exclusion criteria, which were: age less than 15 years and three months; permanent residence outside the Brittany and Loire regions; confirmed bacterial, viral, or parasitic infection; diagnosis of any malignant tumours, and presence of anti-DNA antibody. The criterion of age greater than 15 years and three months was selected based on the French government definition of adult age.

\section{METHODS}

A written survey was performed of all internal medicine and rheumatology practitioners in the Brittany and Loire regions. In order to identify as many practitioners as possible, the 1985 and 1990 'Rosenwald' (the French registry of physicians in practice) and the 1991 telephone directory were consulted. Telephone follow up was performed if the written survey was not returned. The aim of the survey was to find all patients for whom a diagnosis of ASD had been considered during the defined period. In order to eliminate overlap in cases where a patient was seen by two different practitioners, each patient was identified by the first three letters of the first and last name. When an identification was reported twice or more, the practitioners involved were reinterviewed to verify a true repetition. All patient records were then examined by one of the authors (always the same). Two investigators (including the one who gathered the data) determined which patients met the study inclusion criteria for diagnosis. A questionnaire was sent to those patients included in the study, eliciting their medical and social history (profession, exposure to domestic or industrial 
toxic agents, alcohol, tobacco, or drug intoxication, urban or rural housing, infectious or other personal history, family history, composition of the family, date of disease onset, previous travel in foreign countries, domestic pets (dog, cat, birds), and history of similar family pathology).

Patients were classified according to the course of the disease-predominantly systemic (systemic mode) or joint involvement (joint mode). As previously described, the patients with a systemic course were divided into two groups: monocyclic systemic and polycyclic systemic. ${ }^{5}$ A monocyclic systemic course was defined as only one episode of ASD followed by complete clinical and biological remission; the polycyclic systemic course was characterised by at least two episodes of ASD, each one being followed by clinical and biological remission. A chronic joint course was defined by a predominance of joint involvement and by a chronic course associated once (monocyclic chronic joint course) or several times (polycyclic chronic joint course) with systemic manifestations.

CALCULATION OF DISEASE INCIDENCE

An incidence rate was calculated on the basis of the number of cases diagnosed over the last five years of the study. The 1990 census obtained by the Institut National de la Statistique et des Etudes Economiques (INSEE) of Nantes was arbitrarily selected as the total reference population. A total of 4548569 inhabitants over 15 years of age were reported in the Brittany and Loire regions. The mean of new reported cases of ASD per year was divided by the number of inhabitants based on the year 1990 population to obtain the calculated incidence. No significant increase in the population of the Brittany and Loire regions was noted between 1987 and 1991.

\section{Results}

Two hundred and thirty seven practitioners were contacted and 220 responded (93\%) (table 1). Two practitioners refused to participate and 15 were unable to be reached by telephone or mail. A total of 75 patients in whom the diagnosis of ASD had been considered were identified through the survey; after analysis by two investigators, 62 of the 75 cases fulfilled the study inclusion criteria. Two of the 13 patients excluded from the study had high levels of antinuclear antibodies (1/500);

Table 1 Results obtained after mailing the first questionnaire, and patient selection based on recovery of records

\begin{tabular}{llcr}
\hline & $\begin{array}{l}\text { Internal } \\
\text { medicine }\end{array}$ & Rheumatology & Total \\
\hline No of questionnaires & 79 & 158 & 237 \\
Written response (No) & 39 & 18 & 57 \\
Oral response (No) & 38 & 125 & 163 \\
Percent response & 97 & 90 & 93 \\
ASD (No)t & 34 & 28 & 62 \\
\hline
\end{tabular}

+ Number of patients fulfilling the inclusion criteria of adult Still's disease.

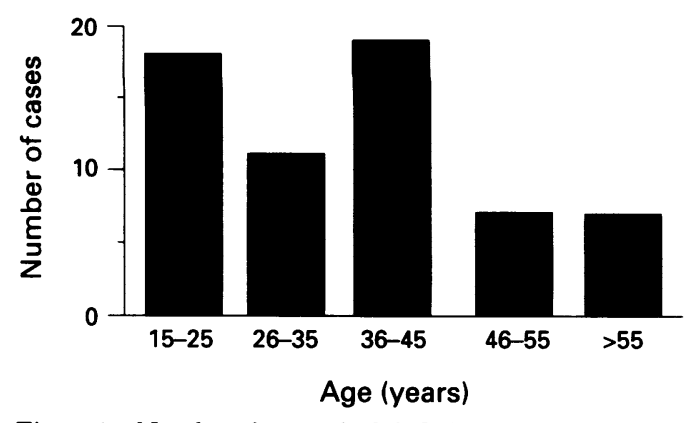

Figure 1 Number of cases of adult Still's disease by age group

two others had the disorder diagnosed during childhood; four presented with only one clinical symptom (fever in three, arthralgia in one), combined with hyperleucocytosis; three patients had the classical triad (fever, arthralgia, eruption), but absence of other clinical symptoms did not permit their inclusion in the study; two patients had a clinical presentation which was not consistent with ASD.

The 62 patients who fulfilled the inclusion criteria included 32 women $(51.6 \%)$ and 30 men $(48 \cdot 4 \%)$. The mean age was 36 years, with two peaks of frequency between 15-25 and 36-45 years (fig .1). The sex ratio in the study population was 1.06 and that in the reference population $1 \cdot 05$.

Table 2 summarises the clinical presentation of the study patients. Antinuclear antibodies other than anti-DNA antibody were noted in five patients $(8 \%)$; in all of them the levels were low and generally transitory. One patient had serum traces of rheumatoid factor (positive latex agglutination test at $1 / 80$, but negative Waaler Rose). Twenty seven patients (44\%) had a monocyclic systemic course and 20 $(32 \%)$ had a polycyclic systemic course. Fifteen patients $(24 \%)$ had a disease course characterised by chronic joint involvement, associated with one systemic episode in four $(6 \%)$ and with several systemic episodes in 11 $(18 \%)$.

Figure 2 shows the numbers of ASD patients recorded per year. From these figures, the yearly incidence can be estimated at 0.16 per 100000 inhabitants above 15 years of age. Seasonal distribution of ASD incidence was also analysed. There were trends for disease to begin in November, April, and August, but no statistically significant difference in incidence was found.

Table 2 Summary of the clinical features and comparison with Pouchot's study'

\begin{tabular}{lll}
\hline Symptoms & \multicolumn{2}{l}{ Percent of cases } \\
\cline { 2 - 3 } & $\begin{array}{l}\text { Our study } \\
(n=62)\end{array}$ & $\begin{array}{c}\text { Pouchot } \\
(n=62)\end{array}$ \\
\hline Fever $\geqslant 39^{\circ} \mathrm{C}$ & $96 \cdot 8$ & 100 \\
Arthralgia \pm arthritis & $96 \cdot 7$ & 100 \\
Cutaneous rash & $77 \cdot 4$ & 87 \\
Hyperleucocytosis & $96 \cdot 8$ & 94 \\
Pharyngitis & $72 \cdot 5$ & 92 \\
Splenomegaly & $22 \cdot 6$ & 55 \\
Increase in AST/ALT & $48 \cdot 3$ & 76 \\
Pleuritis & 16 & 53 \\
Pericarditis & $17 \cdot 7$ & 37 \\
\hline
\end{tabular}

AST $=$ Serum aspartate aminotransferase $;$ ACT $=$ serum ala nine aminotransferase. 


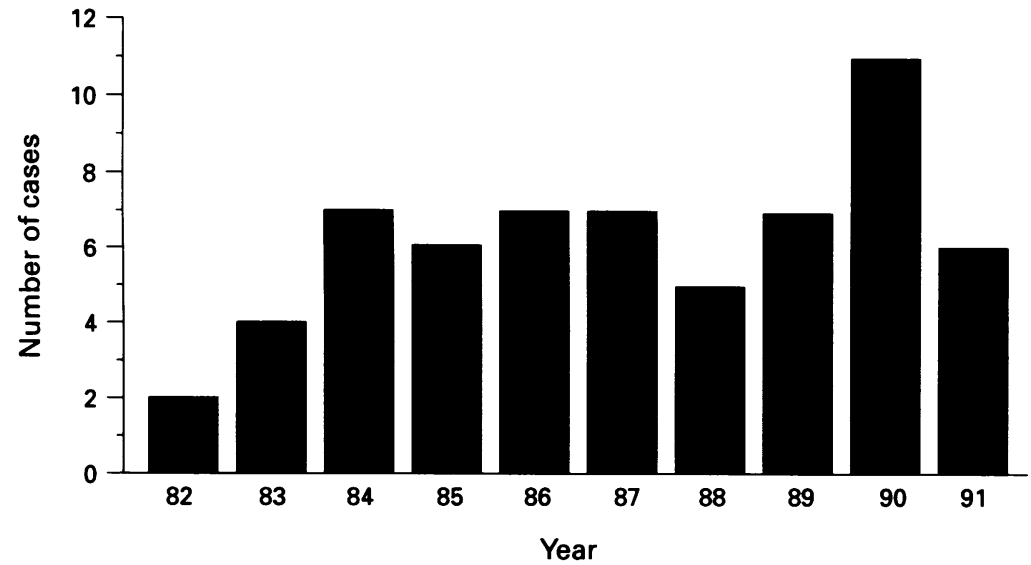

Figure 2 Number of cases of adult Still's disease by calendar year of diagnosis

There was a history of allergy in $22 \cdot 6 \%$ of patients (eight widespread urticaria, four Quincke's oedema, two asthma). A single allergen was associated with the occurrence of ASD episodes in two patients: in the first there was an allergy to an antibiotic (minocyclin chlorhydrate) prescribed for juvenile acne, and in the second there was an allergy to birch catkins.

Because the total number of cases was low, it was not possible to identify an association with any specific risk factors relating to geographical distribution, socioprofessional history, family history, and history of exposure to toxic chemicals.

\section{Discussion}

It is difficulty to assess the yearly incidence of ASD within the general population for many reasons.

First, it is difficult to apply a categorical diagnosis for ASD and it is therefore necessary to use a group of associated criteria. We selected the criteria proposed by Yamagushi et al on the basis of their use in a previous statistical study, but modified them for the reasons stated earlier-for example, the higher frequency of pleuropericarditis in Western countries. Among our 62 patients, one patient did not fulfill the original diagnosis criteria because he presented with only four of the features (fever, arthralgia, hyperleucocytosis, and absence of rheumatoid factor or antinuclear antibodies); however, he fulfilled the modified inclusion criteria because, in addition, he presented with pleuropericarditis. Comparison of our patients' clinical presentation with others previously published in the literature (table 2), ${ }^{9}$ validates our criteria by showing them to be almost identical.

Second, hospital recruitment can introduce an unacceptable bias in patient selection. Because of this, we surveyed both hospital and

Table 3 Incidence rates per year of juvenile rheumatoid arthritis, and of Still's disease within that group, as reported in the literature

\begin{tabular}{|c|c|c|c|}
\hline & Kunamo et al ${ }^{13}$ & Anderson-Gare et al $^{14}$ & Rodary et al ${ }^{15}$ \\
\hline $\begin{array}{l}\text { Population } \\
\text { Incidence of JRA }\end{array}$ & $\begin{array}{l}148362 \\
20 / 100000\end{array}$ & $\begin{array}{l}400600 \\
12 / 100000\end{array}$ & $\begin{array}{l}12265033 \\
3 / 100000\end{array}$ \\
\hline $\begin{array}{l}\text { Incidence of systemic } \\
\text { disease ('Still's') }\end{array}$ & $0.67 / 100000$ & $1 \cdot 3 / 100000$ & - \\
\hline
\end{tabular}

private practitioners. We were unable to contact 17 of the practitioners in the Loire and Brittany regions; the reasons were three refusals, one retirement and 13 unexplained. Knowing the number of cases identified via the responding practitioners, we can speculate that we have possibly missed four or five patients over 10 years.

Third, ASD is not a disease requiring notification to a national public health department. Our study required us to interview practitioners concerning their medical practice over 10 years-a period of time which often required the physicians to rely upon memory. The hospital data were gathered from data banks or updated registries and were more reliable. However, ASD is a rare disease with characteristic symptomatology and is generally remembered by physicians; in addition, most of the private practitioners had patient records that were easily consulted. It is possible that some patients with ASD may have consulted specialists outside the areas studied. Finally, we assumed that all ASD cases in the Brittany and Loire regions were seen, at least once, by an internal medicine or rheumatology practitioner.

To facilitate our calculations, we used the 1990 census to obtain a number for the reference population. It was an arbitrary selection, but allowed an estimate of the average population in 1989 , the median year of the study. For this reason, the incidence was calculated using only the five last years of the study. In a retrospective study of a disease which may develop over several years and for which diagnosis may be delayed, it is difficult to calculate an exact incidence rate. This is why we used the date of diagnosis to calculate the incidence. The mean delay between initial symptoms and diagnosis in our patient population was 15 weeks (SD 7.4), with an upper limit of one year except in one case. We believe this reduced the potential risk for inclusion of prevalent rather than incident cases.

Taking into account these assumptions, the yearly incidence of ASD was estimated to be $0 \cdot 16$ per 100000 inhabitants. This incidence is lower than those reported elsewhere among juvenile rheumatoid arthritis (JRA) patients, which varied from 0.67 to 1.3 per 100000 children (table 3). ${ }^{13-15}$ The difference in estimation of the incidence in the three publications on JRA indicates the difficulty of such studies, but is also directly related to the different clinical presentations and courses of the disease, and to the variability of the study methods.

The clinical presentation of patients in our study was in agreement with other studies published in the literature. ${ }^{1-11}$ ASD is a disease of young adults (15-25 years) ${ }^{6}$ but can affect patients older than 60 years of age. ${ }^{16} 17$ The second peak of frequency noted in our study was unexpected. A mean age of 36 years has already been described ${ }^{18}$ and suggests that the age distribution in ASD is not unimodal. The mean age of our patients referred from internal medicine $(37 \cdot 1)$ was the same as that of the patients referred from rheumatology $(32.5)$ 
(Kruskall and Wallis test), and the clinical presentation of the patients older and younger than 30 years of age was similar. The first publication on ASD included only women, ${ }^{1}$ but several studies since then have demonstrated the sex ratio to be close to $1 .{ }^{6910}$ This also was supported by our work, which compared an ASD population with a reference population for the first time.

One hypothesis for the pathogenesis of ASD is the existence of an allergic reaction to an infectious factor; $;^{19}{ }^{20}$ however, this hypothesis has never been proved. Our study shows that among the patients with ASD, 23\% had a history of allergy; in the general population, the frequency is $10-24 \%{ }^{21}{ }^{22}$-lower than that in our population of patients with ASD. Further studies to investigate a possible association between atopy and ASD would be of interest.

As the aetiopathology of ASD remains unknown, it is necessary to research immune, infectious, and environmental factors. Advances in molecular biology will enable us to approach more closely the true mechanism of the disease. Further studies are necessary, particularly in the field of epidemiology, to discover the risk factors associated with this disease. Case-control studies enabling us to obtain an answer to this question have not yet been performed.

In conclusion, this work is the only study to have defined an approximation of the incidence of ASD. To obtain a more precise measure of the incidence, it would be necessary to perform a prospective study, but this would be a difficult undertaking because of the rarity of the disease.

We are grateful to Dr Baldous, Pr Boasson, Pr Cartier, Dr Corcos, Dr Cornu, Dr Desfois, Dr De Treglode, Dr Dien, Pr Fressinaud, Pr Le Goff, Dr Louis, Dr Machevin, Dr Maisonneuve, Dr Martin, Dr Marchessaud, Dr Minssart, $\mathrm{Pr}$ Mottier, Pr Pawlotsky, Dr Perreaut, and Dr Thorel for referring patients to this study.

We wish to thank Nina Hanif French from the university of Louisville, Kentucky, USA, for her help with the translation to English.
1 Bywaters E G L. Still's disease in the adult. Ann Rheum Dis 1971; 30: 121-33.

2 Aptekar R J, Decker J, Bujak J S, Wolff S. Adult onse juvenile rheumatoid arthritis. Arthritis Rheum 1973; 16: 715-8.

3 Auquier L, Debray J, Paolaggi J B, Krulik M, Henrard J C. Fièvre prolongée révelatrice d'un rhumatisme inflammatoire de l'adulte. Ann Méd Interne 1971; 122 597-603.

4 Bujak J S, Aptekar R J, Decker J, Wolff S M. Juvenile theumatoid arthritis presenting in the adult as fever of rheumatoid arthritis presenting in the adult
unknown origin. Medicine 1973; 52: 431-4.

5 Cusch J J, Medsger T A, Christy W C, Herbert D C Cooperstein L A. Adult onset Still's disease clinical course Cooperstein L A. Adult onset Still's disease clinical

6 Lammle B, Schroder E, Steiger U. Systemische Juvenile Chronische Arthritis (M.Still) bei Erwachsenen. Ubersicht die Literatur. Schweiz Med Wochenschr 1983; 113 126-37.

7 Larson E B. Adult Still disease: Evolution of a clinical syndrome and diagnosis, treatment and follow up of 17 patients. Medicine 1984; 63: 82-91.

8 Medsger T A, Christy W C. Carpal arthritis with ankylosis in late onset Still's disease. Arthritis Rheum 1976;19: in late onse.

9 Pouchot J, Sampalis J, Beaudet F, et al. Adult Still's disease: manifestations, disease course and outcome in 62 patients. Medicine 1991; 70: 118-36.

10 Ohta A, Yamaguchi M, Kaneoka H, Nagayashi T, Hida M. Adult Still disease: review of 228 cases from the literature. f Rheumatol 1987; 14: 1139-46.

11 Ohta A, Yamaguchi M, Tsunematsu T, et al. Adult Still's disease: a multicenter survey of Japanese patients. Rheumatol 1990; 17: 1058-63.

12 Yamaguchi $M$, Ohta A, Tsunematsu $T$, et al. Preliminary criteria for classification of adult Still's disese. $\mathcal{F}$ Rheumatol 1992; 19: 424-30

13 Kunnamo I, Kallio P, Pelkonen P. Incidence of arthritis in urban Finnish children-a prospective study. Arthritis Rheum 1986; 29: 1232 .

14 Anderson-Gare B, Fasth A, Anderson J. Incidence and prevalence of juvenile chronic arthritis: a population survey. Ann Rheum Dis 1987; 46: 277.

15 Rodary C, Hayem F, Mozziconnacci P. Essai d'enquête concernant l'incidence de l'arthrite chronique juvenile en France (année 1972). Ann Pédiatr 1977; 24: 424

16 Steffe L A, Cooke C L. Still's disease in a 70-year-old woman. $\mathcal{f} A M A$ 1983; 249: 2062-3.

17 Wouters J, Van Rijswijk M, Van de Putte L. Adult onset Still's disease in the elderly: a report of two cases. $\mathcal{f}$ Rheumatol 1985; 12: 791-3.

18 Godeau B, Leport C, Perronne C, Salmon-Cerron D, Kahn M-F, Vilde J L. Aspects évolutifs de la maladie de Still M-F, Vilde J L. Aspects evolutifs de la maladie de Still de l'adulte. A propos

19 Wissler $H$. Über eine besondere Form sepsiähnlicher Krankheiten (Subsepsis hyperergica) Monatsschr Kinderheilk 1943; 94: 51-68.

20 Fanconi G. Über einen fall von Subsepsis allergica Wissler Helv Paediatr Acta 1946; 6: 532-7.

21 Visscher M O, Hanifin J M, Bowman W J, Reed B R. Atopic dermatitis and atopy in non-clinical populations. Acta Derm Venereol Suppl (Stockh) 1989; 144: 34-40.

22 Larregue $M$. Atopie et dermatite atopique, répartition dans la population générale. In: Lorette $G$, Vaillant $L$ eds. Les eczema-dermatologie pratique. Paris: Doin, 1992; 165-6. 